\title{
Supplementary Data for
}

\section{Post- Excitation Transient IR phenomena in $\alpha-\mathrm{Fe}_{2} \mathrm{O}_{3}$ films Andraž Šuligoj, ${ }^{1,2,3}$ Dorit Grinberg ${ }^{1}$ and Yaron Paz ${ }^{1}$}

${ }^{1}$ Technion - Israel Institute of Technology, Haifa, Israel

${ }^{2}$ University of Ljubljana, Ljubljana, Slovenia

${ }^{3}$ National Institute of Chemistry, Ljubljana, Slovenia

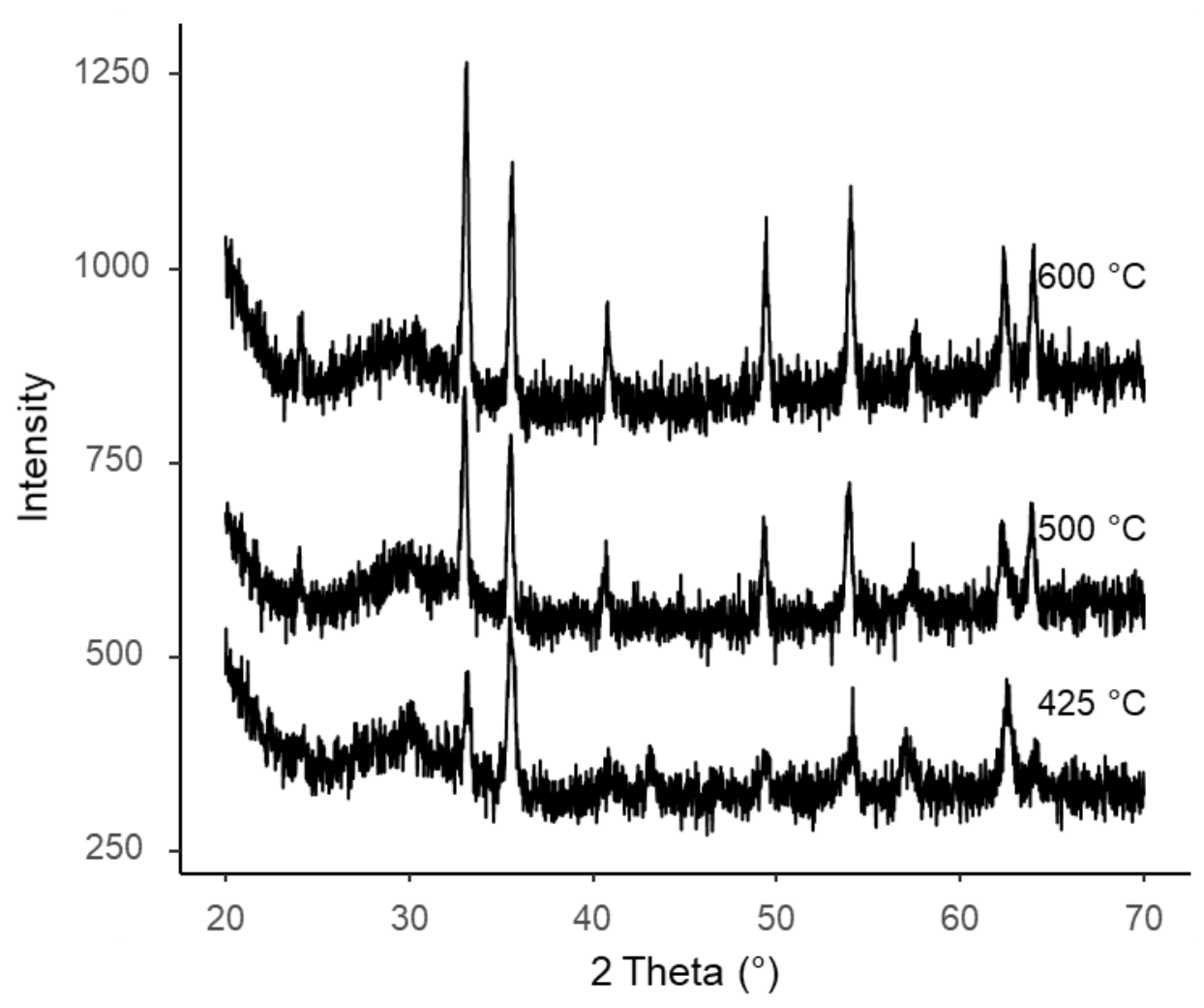

Figure S1. XRD pattern of hematite prepared at three different temperatures. 


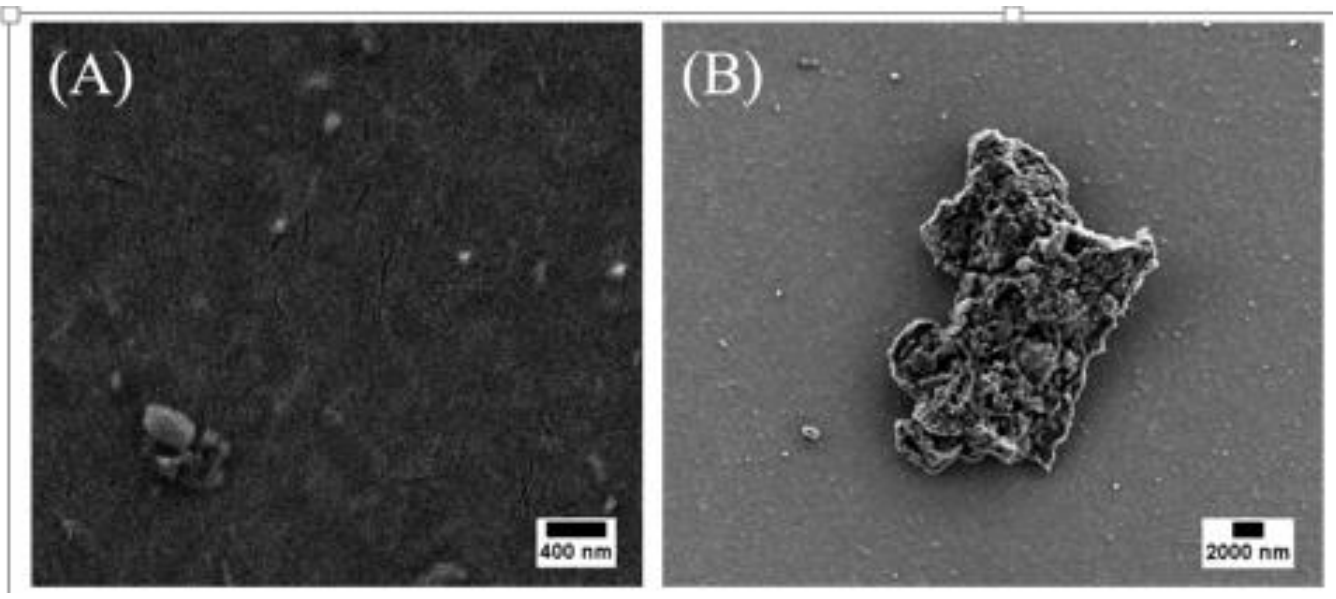

Figure S2. SEM micrographs of hematite particles and aggregates (A and B). 

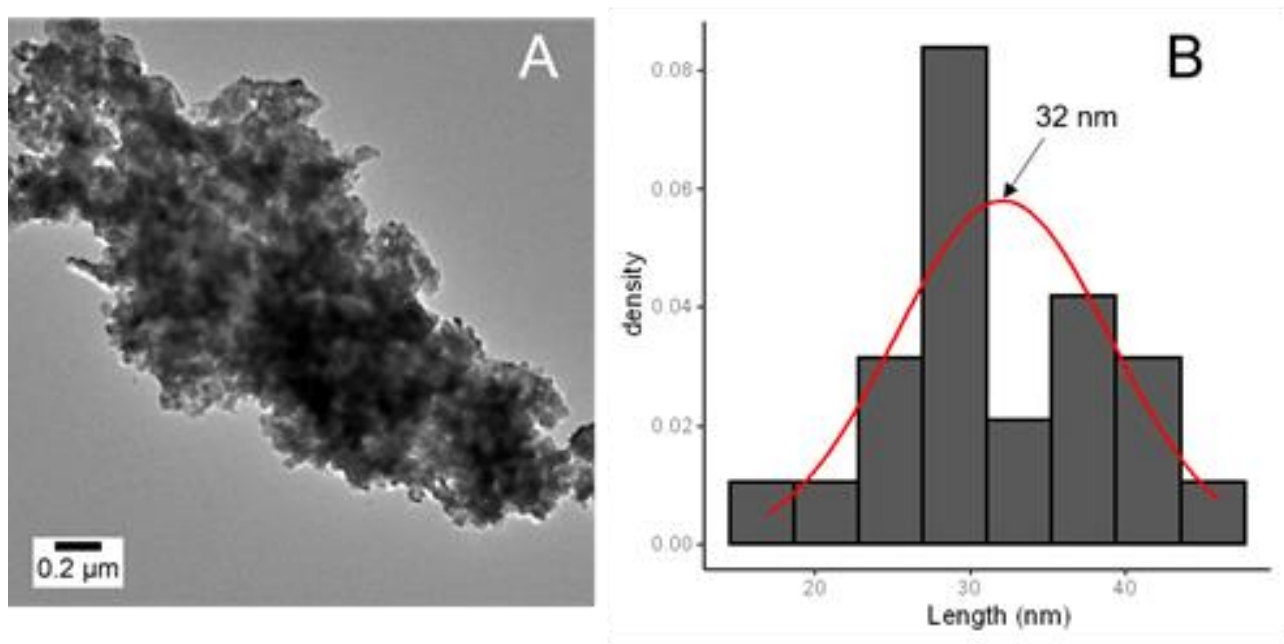

Figure S3. TEM micrographs of hematite powders synthesised at $500{ }^{\circ} \mathrm{C}(\mathrm{A})$ and size distribution histogram with a corresponding gaussian fitting (B). 


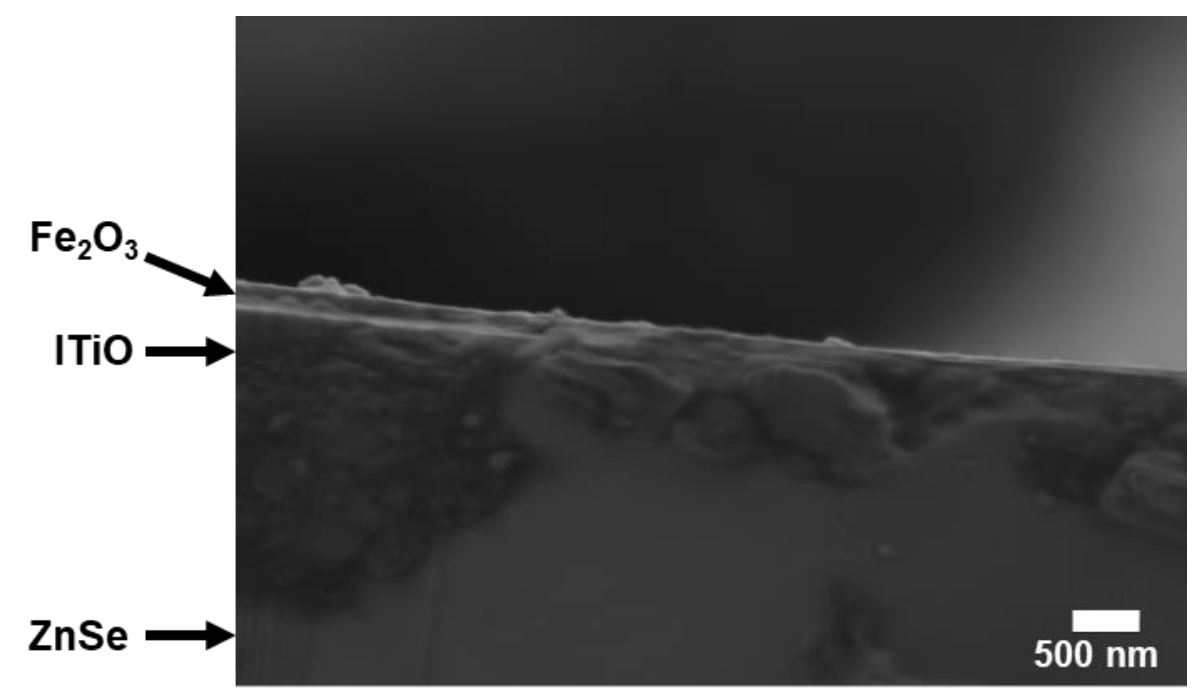

Figure S4. SEM cross-cut image of $\mathrm{ZnSe}$ coated with one layer of hematite calcined at $500{ }^{\circ} \mathrm{C}$. 


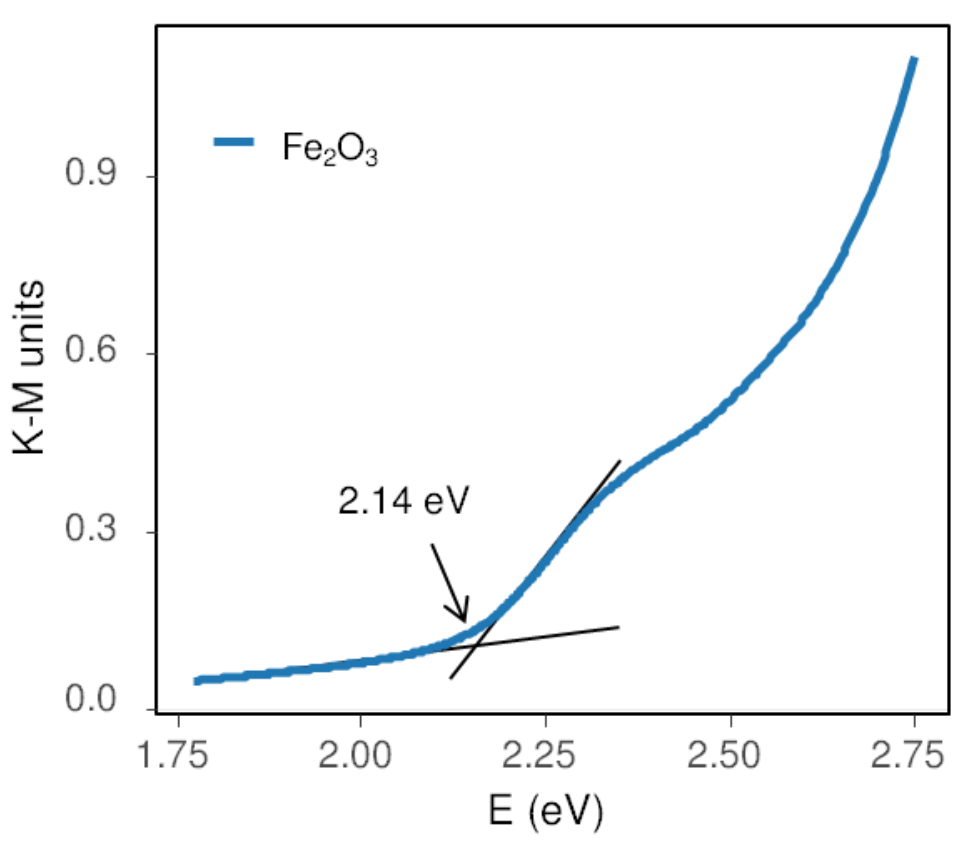

Figure S5. Tauc plot of the hematite layer sintered at $500{ }^{\circ} \mathrm{C}$ and the corresponding band gap determination by extrapolating the onset absorbance curve. 